\title{
Specific Lipopolysaccharide Serotypes Induce Differential Maternal and Neonatal Inflammatory Responses in a Murine Model of Preterm Labor
}

\author{
Roberta Migale, ${ }^{*}$ Bronwen R. Herbert, ${ }^{\dagger \dagger}$ Yun S. Lee, ${ }^{*}$ Lynne Sykes, ${ }^{*}$ Simon N. Waddington, ${ }^{\ddagger}$ Donald Peebles, \\ Henrik Hagberg, ${ }^{\| *}$ Mark R. Johnson, ${ }^{* \dagger}$ Phillip R. Bennett, ${ }^{*}$ and David A. MacIntyre*
}

\begin{abstract}
From the Imperial College Parturition Research Group, * Institute of Reproductive and Developmental Biology, Imperial College London, London, United Kingdom; the Academic Department of Obstetrics and Gynaecology, ${ }^{\dagger}$ Chelsea and Westminster Hospital, London, United Kingdom; the Gene Transfer Technology Group ${ }^{\ddagger}$ and the UCL Centre for Perinatal Brain Protection \& Repair, "Institute for Women’s Health, University College London, London, United Kingdom; the Antiviral Gene Therapy Research Unit, ${ }^{\S}$ Faculty of Health Sciences, University of the Witswatersrand, Johannesburg, South Africa; the Department of Clinical Sciences, "Perinatal Center, University of Gothenburg, Gothenburg, Sweden; and the Division of Imaging Sciences and Biomedical Engineering, ** Centre for the Developing Brain, King's College London, King's Health Partners, St. Thomas' Hospital, London, United Kingdom
\end{abstract}

Accepted for publication

May 21, 2015.

Address correspondence to David A. MacIntyre, Ph.D., Imperial College Parturition Research Group, Institute of Reproduction and Developmental Biology, Imperial College London, Hammersmith Campus, Du Cane Road London W12 0NN, United Kingdom. E-mail: d.macintyre@imperial.ac.uk.

\begin{abstract}
Intrauterine inflammation is recognized as a key mediator of both normal and preterm birth but is also associated with neonatal neurological injury. Lipopolysaccharide (LPS) is often used to stimulate inflammatory pathways in animal models of infection/inflammation-induced preterm labor; however, inconsistencies in maternal and neonatal responses to LPS are frequently reported. We hypothesized that LPS serotype-specific responses may account for a portion of these inconsistencies. Four different Escherichia coli LPS serotypes (0111:B4, 055:B5, 0127:B8, and 0128:B12) were administered to CD1 mice via intrauterine injection at gestational day 16 . Although control animals delivered at term $60 \pm 15$ hours postinjection (p.i.), those administered with 0111:B4 delivered $7 \pm 2$ hours p.i., 055:B5 delivered $10 \pm 3$ hours p.i., 0127:B8 delivered $16 \pm 10$ hours p.i., and 0128:B12 delivered $17 \pm 2$ hours p.i. (means \pm SD). A correlation between the onset of preterm labor and myometrial activation of the inflammatory transcription factor, activator protein 1 , but not NF- $\kappa B$ was observed. Specific LPS serotypes induced differential activation of downstream contractile and inflammatory pathways in myometrium and neonatal pup brain. Our findings demonstrate functional disparity in inflammatory pathway activation in response to differing LPS serotypes. Selective use of LPS serotypes may represent a useful tool for targeting specific inflammatory response mechanisms in these models. (Am J Pathol 2015, 185: 2390-2401; http://dx.doi.org/10.1016/j.ajpath.2015.05.015)
\end{abstract}

Preterm birth and its associated complications are now the leading cause of death among children $<5$ years. ${ }^{1}$ A lack of knowledge of the basic molecular mechanisms orchestrating the onset of preterm and term labor has prevented advancements being made in early diagnosis and has inhibited the design of effective treatments. Evidence from both human and animal studies indicates that activation of inflammatory pathways in gestational tissues is a shared mechanism common to both normal and preterm birth. ${ }^{2,3}$ Intrauterine inflammation is also associated with fetal brain injury, which may lead to longterm neurological disorders, such as cerebral palsy. ${ }^{4,5}$ An increasing body of evidence supports the involvement of inflammation also, in the absence of overt infection, in preterm birth. $^{2}$ A key mediator of the inflammatory response in gestational tissues at the time of labor is NF- $\kappa$ light chain enhancer of activated B cells $(\mathrm{NF}-\kappa \mathrm{B})$; however, data have also implicated activator protein 1 (AP-1) and CCAAT/enhancer-binding proteins (C/EBPs) in the

Supported by the Wellcome Trust grant DSRR_P24225 (S.N.W., D.P., H.H., M.R.J. and P.R.B.), the Arthur Haffenden Fund (R.M., D.A.M., and P.R.B.), and the Medical Research Council Career Development Award MR/L009226/1 (D.A.M.).

The views expressed herein are of the authors and not an official position of the institutions or funders.

Disclosures: None declared. 
regulation of inflammatory pathways associated with the onset of labor. $^{6-9}$

In various animal models of preterm labor (PTL), the Gram-negative bacterial cell wall component, lipopolysaccharide (LPS), is administered systemically to mimic bacterial infection during pregnancy or locally via an intrauterine injection to reflect ascending vaginal infection and/or chorioamnionitis. ${ }^{10-21}$ Recognition of the LPS molecule by Toll-like receptors (TLRs), expressed on the surface of intrauterine cells, ${ }^{15,21}$ activates an inflammatory cascade that drives proinflammatory cytokine production and, subsequently, the release of prostaglandins, cytokines, and chemokines promoting cervical ripening, uterine activation, and contractility. ${ }^{14,22}$ Although the inflammatory response to LPS appears to be consistently achieved in mouse models of preterm birth, significant variation in the timing of preterm birth and neonatal survival outcomes is often reported, only a proportion of which can be attributed to differences in experimental design (eg, gestation age at time of injection, site of administration, animal species/ strain, and LPS dose).

The LPS molecule is composed of a complex glycolipid containing a lipid A moiety (phosphorylated glucosamine disaccharide with multiple fatty acid chains), an oligosaccharide core, and an extending glycan polymer referred to as the $\mathrm{O}$-antigen. The sugar composition of this polysaccharide side chain determines the serological specificity of the molecule, whereas the lipid A group typically confers toxicity. ${ }^{23}$ Previous studies in rat models of hypothermia and albumin extravasation have reported functional differences caused by LPS serotype specificity. ${ }^{24,25}$ Treatment of fever with the selective cyclooxygenase (COX)-2 inhibitor, 4-[5-(4-chlorophenyl)-3-(trifloromethyl)-1H-pyrazol-1-yl] benzenesulfonamide (SC-58236), is effective in the initial phase of animals administered with Escherichia coli O55:B5 LPS, but not those administered with E. coli O111:B4 LPS. ${ }^{26,27}$ Moreover, different E. coli LPS serotypes can be associated with defined clinical syndromes of enteric/diarrheal disease. ${ }^{28,29}$ Collectively, these data indicate serotype-specific activation of inflammatory pathways that translates into variable phenotypic responses. In the context of animal models of infection/inflammation-induced PTL, this could involve differential activation of the key inflammation-mediated pathways preceding labor, thus leading to differential maternal and neonatal outcomes. Therefore, we hypothesized that LPS serotypes elicit specific maternal and neonatal innate immune responses that involve differential activation of inflammatory pathways.

By using four different $E$. coli LPS serotypes (O111:B4, O55:B5, O127:B8, and O128:B12), we demonstrate functional disparity in LPS serotype activation of inflammatory pathways in the uterus and the pup brain. Our results indicate that the use of specific LPS serotypes may provide a useful tool for the selective activation of specific inflammatory response mechanisms in animal models of preterm birth.

\section{Materials and Methods}

\section{Murine Studies and Ethics Statement}

Animal studies were performed under UK Home Office License 70/6906, in accordance with the guidance to Animals Scientific Procedures Act of 1986, and with approval of the Imperial College London and University College London (London, UK) Ethical Review Committees. CD1 outbred virgin females were timed mated, and the presence of a copulatory plug was classified as embryonic day 0 (E0) of gestation. Mice were housed in open cages at $21^{\circ} \mathrm{C} \pm 1{ }^{\circ} \mathrm{C}$ with ad libitum access to standard rodent food and water and were exposed to a 12:12 light-dark cycle regimen. Unless otherwise stated, five biological replicates were collected for all experimental groups.

\section{Murine Model of Inflammation-Induced PTL}

Pregnant (E16) female dams were administered a s.c. injection of $2.5 \mathrm{mg} / \mathrm{kg}$ morphine 20 minutes before surgery. Animals were anesthetized by isoflurane, and a laparotomy was performed as previously described. ${ }^{9,30,31}$ Briefly, both uterine horns were exteriorized and the number of live fetuses per horn was recorded. An intrauterine injection of 20 $\mu \mathrm{g}[25 \mu \mathrm{L}$ total volume in phosphate-buffered saline (PBS)] of either E. coli LPS serotype O111:B4, O55:B5, O127:B8, or O128:B12 (Sigma Aldrich, Gillingham, UK) or sterile PBS was injected into the upper right uterine horn between the first and second sacs. Biochemical characteristics of the LPS serotypes were consistent [phenol extracted; protein content, $\leq 3 \%$; solubility, 4.9 to $5.1 \mathrm{mg} / \mathrm{mL}$; endotoxin level, $\geq 500,000$ endotoxin units $(\mathrm{EU}) / \mathrm{mg}]$. Animals were continuously monitored after surgery remotely via an infrared closed circuit TV camera system during recovery until tissue collection or the onset of spontaneous delivery. The onset of labor was defined as delivery of the first pup.

\section{Tissue Collection}

For tissue collection, mice were anesthetized and sacrificed by cervical dislocation. A laparotomy was performed, uteri were immediately incised in the longitudinal direction, and pups were isolated and sacrificed by decapitation. Right and left horns of the uterus were snap frozen separately after removal of gestational membranes, placentas, and vasculature. Myometrium samples from the right uterine horns were used for mRNA and protein analyses. After decapitation, whole pup brains were isolated and snap frozen. Tissue was stored at $-80^{\circ} \mathrm{C}$ until extraction. Before culling, pup viability was qualitatively assessed using a scoring system as follows: 3, pups displaying full body spontaneous movement when removed from the myometrium or amniotic sac; 2, pups with partial body movement (ie, lower half or full body movement when gently prodded with forceps); 1 , pups exhibiting partial body movement or movement of 
limbs only in response to forceful prodding or squeezing of a limb with forceps' and 0, pups with no response when forcefully prodded or limbs squeezed.

\section{Protein Extraction and Western Blot Analysis}

Myometrial and whole pup brain protein lysates were prepared by grinding tissue under liquid nitrogen in a mortar and pestle, then homogenizing in a modified radioimmunoprecipitation assay buffer (1\% Triton X-100, 1\% 3-[(3-cholamidopropyl)dimethylammonio]-1-propanesulfonate, $0.1 \%$ SDS, $1 \%$ deoxycholic acid, $50 \mathrm{mmol} / \mathrm{L} \mathrm{NaF}, 1 \mathrm{mmol} / \mathrm{L}$ orthovanadate, protease inhibitor cocktail, $25 \mathrm{mmol} / \mathrm{L}$ Tris [pH 7.4], and 150 $\mathrm{mmol} / \mathrm{L} \mathrm{NaCl}$ ) at a ratio of $1 \mathrm{~mL}$ buffer: $100 \mathrm{mg}$ wet weight tissue. Protein lysates were centrifuged at $13,000 \times g$, and protein concentration was determined via a Bradford assay (Bio-Rad, Hemel Hempstead, Hertfordshire, UK). Extracted proteins ( $20 \mu \mathrm{g}$ per sample) were separated by SDS-PAGE and transferred to a polyvinylidene difluoride membrane (GE Healthcare, Little Chalfont, UK) at $100 \mathrm{~V}$ (constant voltage) at $4^{\circ} \mathrm{C}$. Membranes were blocked with 5\% skim milk in Trisbuffered saline (TBS) supplemented with $0.01 \%$ Tween 20 (TBST) for 1 hour and then incubated overnight at $4^{\circ} \mathrm{C}$ with primary antibodies raised against phosphorylated (p) NF- $\mathrm{KB}$ : p65 Ser536 (1:1000 in TBS; catalog number 3031; Cell Signaling Technology, Hitchin, Herts, UK), p-c-Jun Ser73 (1:1000 in TBST containing 1\% milk; catalog number 9164; Cell Signaling Technology); CX43 (1:1000 in TBST containing 1\% milk; catalog number 3512; Cell Signaling Technology); $\mathrm{p}-\mathrm{C} / \mathrm{EBP} \beta \mathrm{Thr} 235$ (1:1000 in 1\% bovine serum albumin; catalog number 3084; Cell Signaling Technology); COX-2 (1:2000 in TBST containing 5\% milk; catalog number sc1745; Santa Cruz Biotechnology, Dallas, TX); and IL-1 $\beta$ (1:1000 in TBST containing 1\% milk; catalog number AF-401NA; R\&D Systems, Abingdon, UK). After primary antibody incubation, membranes were washed six times (5 minutes each) with TBST and subsequently incubated with the appropriate horseradish peroxidase-conjugated secondary antibody for 1 hour at room temperature (1:2000; Cell Signaling Technology) before being washed again with TBST. Detection of immunoreactive bands was performed by enhanced chemiluminescence (ECL; GE Healthcare) using the ImageQuant LAS 4000 Imager (GE Healthcare). Membranes were stripped with $0.2 \mathrm{~mol} / \mathrm{L} \mathrm{NaOH}$ for 5 minutes at room temperature, washed in TBST, and reprobed with $\beta$-actin (1:40,000; Sigma Aldrich) as a loading control. Densitometric analysis was conducted using ImageQuant TL (GE Healthcare).

\section{RNA Isolation and Real-Time Quantitative RT-PCR}

mRNA was isolated from ground myometrial and whole pup brain tissue using the Nucleospin miRNA kit (MachereyNagel, Düren, Germany) following the manufacturer's instructions. RNA concentration and integrity were measured with a NanoDrop 1000 spectrophotometer (ThermoScientific, Waltham, MA) and an Agilent 2100 bioanalyzer (Agilent Technologies, Santa Clara, CA). cDNA synthesis was performed on $2 \mu \mathrm{g}$ RNA using M-MLV Reverse Transcriptase (Sigma-Aldrich). RNA was incubated with $1 \mu \mathrm{L}$ of $0.5 \mu \mathrm{g} / \mu \mathrm{L}$ Oligo(dT) 23 Primers Anchored (Sigma-Aldrich) and $1 \mu \mathrm{L}$ of $10 \mathrm{mmol} / \mathrm{L} \mathrm{dNTP} \mathrm{mix} \mathrm{(Sigma-Aldrich)} \mathrm{for} 10$ minutes at $70^{\circ} \mathrm{C}$ and then transferred onto ice. Master mix $(10 \mu \mathrm{L})$ containing $6.5 \mu \mathrm{L}$ of nuclease-free water, $2 \mu \mathrm{L}$ of M-MLV Reverse Transcriptase Buffer, $0.5 \mu \mathrm{L}$ of human ribonuclease inhibitor (40,000 U/mL; Sigma-Aldrich), and $1 \mu \mathrm{L}$ of $200 \mathrm{U} / \mu \mathrm{L}$ MMLV Reverse Transcriptase was added to each RNA sample and incubated at room temperature for 15 minutes, then at $37^{\circ} \mathrm{C}$ for 50 minutes, and finally at $85^{\circ} \mathrm{C}$ for 10 minutes to inactivate the enzyme. Isolated cDNA was stored at $-20^{\circ} \mathrm{C}$. For each target gene, a gene-specific primer set of 8 to $22 \mathrm{bp}$ was designed using the National Center for Biotechnology Information Database (http://www.ncbi.nlm.nih.gov/tools/ primer-blast, last accessed April 29, 2015) with optimal $\mathrm{T}_{\mathrm{m}}$ of $60^{\circ} \mathrm{C}$ (Table 1). Both forward and reverse primers were designed to span exon-exon junctions.

Real-time quantitative RT-PCR was performed in 384-well plates in duplicate using a total volume of $10 \mu \mathrm{L}$ containing 2.6- $\mu \mathrm{L}$ nuclease-free water, $0.1 \mu \mathrm{L}$ ROX reference dye (Sigma-Aldrich), $0.15 \mu \mathrm{L}$ forward primer $(20 \mu \mathrm{mol} / \mathrm{L}), 0.15$ $\mu \mathrm{L}$ reverse primer $(20 \mu \mathrm{mol} / \mathrm{L}), 5 \mu \mathrm{L}$ SYBR Green JumpStart Taq ReadyMix (Sigma-Aldrich), and $2 \mu \mathrm{L}$ of cDNA. Reactions were run on an ABI 7900HT (Applied Biosystems

Table 1 Primer Sequences Used for Real-Time Quantitative RT-PCR

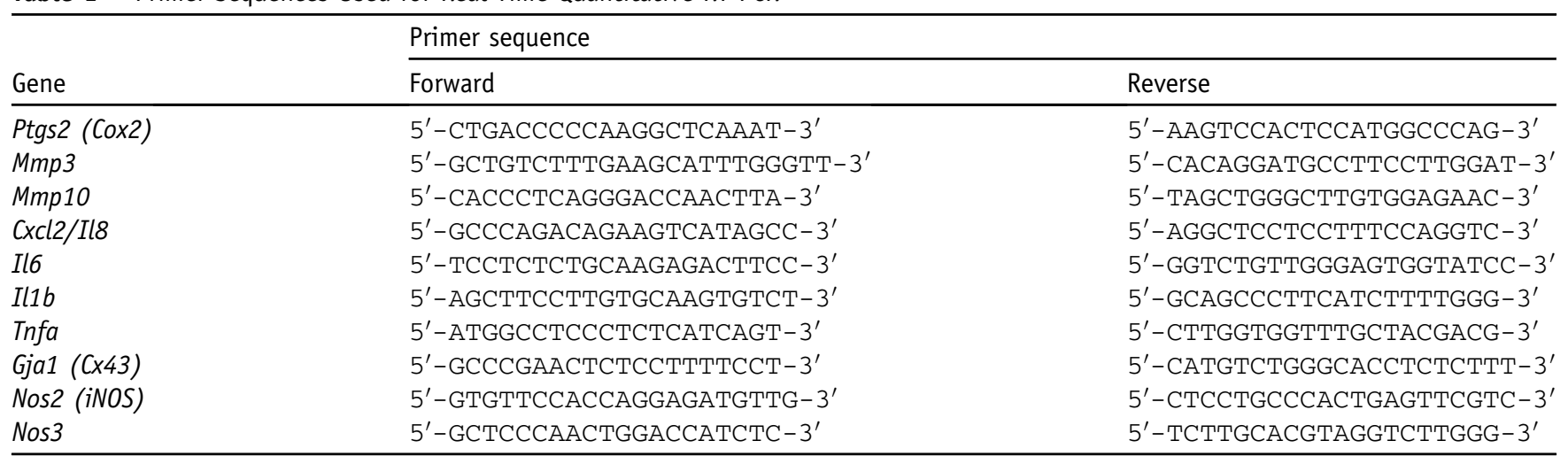


Foster City, CA) as follows: 2 minutes at $94^{\circ} \mathrm{C}$ and 40 cycles of 15 seconds at $94^{\circ} \mathrm{C}, 60$ seconds at $60^{\circ} \mathrm{C}$, and 60 seconds at $72^{\circ} \mathrm{C}$; the dissociation curve was 15 seconds at $95^{\circ} \mathrm{C}, 1$ minute at $60^{\circ} \mathrm{C}$, and 15 seconds at $95^{\circ} \mathrm{C}$. Data were processed using ABI 7900HT SDS version 2.4 software and analyzed with Excel (Office 2010; Microsoft, Redmond, WA). Gene expression levels for each sample were normalized to the endogenous reference $\beta$-actin mRNA for each well $\left(\Delta \mathrm{C}_{\mathrm{T}}\right)$. Relative efficiencies of gene target and endogenous control amplification were assessed using standard curves generated for each gene by 10 -fold serial dilutions of the same sample run in duplicate. The comparative $\mathrm{C}_{\mathrm{T}}$ method was used to determine differences between LPS- and PBS-treated control samples. Dissociation curve analysis, confirmed by $2 \%$ agarose gel electrophoresis, was used to verify that a single gene-specific product was produced (data not shown).

\section{Statistical Analysis}

Each experiment consisted of five biological replicates, and results are presented as means \pm SD unless otherwise specified.

Densitometric values were normalized to $\beta$-actin before undertaking statistical analyses using GraphPad Prism 5.0 (GraphPad Software, San Diego, CA). The statistical significance between LPS- and PBS-treated control samples was assessed using a two-tailed $t$-test or one-way analysis of variance (with Tukey's post hoc test) where appropriate. $P<0.05$ was considered statistically significant. For linear regression, mean levels of $\mathrm{p}$-c-Jun normalized to $\beta$-actin for each serotype at 6 hours after injection were calculated and regressed against mean time of delivery for each serotype. The coefficient of determination $\left(r^{2}\right)$ of the linear regression was calculated and reported as a measure of goodness of fit.

\section{Results}

\section{E. coli-Derived LPS Serotypes Induce Different Maternal and Neonatal Outcomes in a Murine Model of PTL}

To characterize the effects of different LPS serotypes on PTL induction and neonatal outcome in mice, pregnant dams received an upper-intrauterine injection of $20 \mu \mathrm{g}$ of E. coli-derived LPS serotype O111:B4, O55:B5, O127:B8, or O128:B12 on E16. Although control dams administered PBS delivered approximately $60 \pm 15$ hours postinjection (p.i.) at term, animals injected with O111:B4 delivered $7 \pm 2$ hours p.i., O55:B5 delivered $10 \pm 3$ hours p.i., O127:B8 delivered $16 \pm 10$ hours p.i., and O128:B12 delivered $17 \pm 2$ hours p.i. (data are given as means $\pm \mathrm{SD}$ ) (Figure 1A). The percentage of dams who delivered preterm with each serotype was $100 \%$, where preterm birth was defined as delivery before 36 hours postinjection. Major differences were also observed in fetal viability at 6 hours after LPS administration (Figure 1B). Pup survival rates in dams injected with PBS or O128:B12 were 100\%, with pups displaying a strong
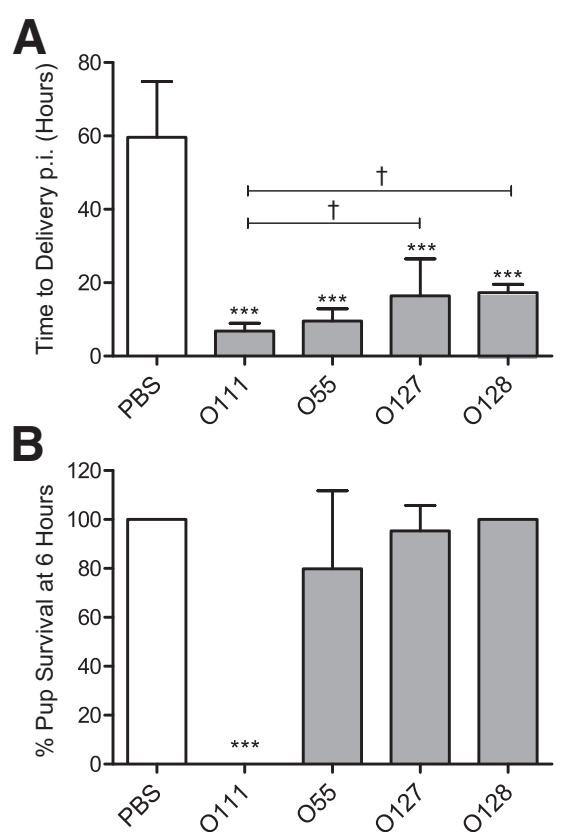

Figure 1 Specific Escherichia coli lipopolysaccharide (LPS) serotypes induce differential maternal and neonatal outcomes in a murine model of preterm labor. A: The mean time of delivery of control dams administered an upper intrauterine injection of phosphate-buffered saline (PBS) is $60 \pm 4$ hours postinjection (p.i.), whereas those administered 0111:B4 deliver $7 \pm$ 1 hours p.i., 055:B5 deliver $10 \pm 1$ hours p.i., 0127:B8 deliver $16 \pm 4$ hours p.i., and 0128:B12 deliver $17 \pm 1$ hours p.i. B: Pup viability rates at 6 hours postinjection are 100\% for PBS and 0128:B12-treated dams; however, in the case of 0111:B4, all pups die at 6 hours. Pup viabilities for 055:B5 and 0127: B8 serotypes are $80 \%$ and $95 \%$, respectively. ${ }^{* *} P<0.001$ indicates significant differences compared with PBS-injected control dams; ${ }^{\dagger} P<0.05$ indicates significant differences within the LPS treatment group (one-way analysis of variance with Tukey's post hoc analysis). $n=5$ (A and $\mathbf{B}$ ).

response to mechanical stimuli. However, in animals injected with LPS O111:B4, no surviving pups were observed 6 hours p.i. Pup survival rates for O55:B5 and O127:B8 serotypes were $80 \%$ and $95 \%$, respectively, with pups displaying a reduced response to mechanical stimuli compared with PBS control or O128:B12 treated animals.

\section{Activation of Myometrial AP-1 Is Associated with the Onset of PTL}

To investigate transcription factors potentially involved in modulating inflammation preceding myometrial contractile activation in response to LPS serotype treatment, Western blot analysis was used to examine the phosphorylation status of three key inflammatory transcription factors (NF- $\mathrm{BB}, \mathrm{AP}-1$, and $\mathrm{C} / \mathrm{EBP} \beta$ ) in myometrium samples collected from treated and control animals 6 hours after injection, before delivery (Figure 2, A and B). Administration of LPS O111:B4 led to a 3.4-fold increase in the phosphorylation of the AP-1 subunit, p-c-Jun, compared with PBS control [means \pm SD, $7.9 \pm 6.2$ arbitrary units (AUs) and $2.3 \pm 1.6$ AUs, respectively; $P<0.05]$. Induction of p-c-Jun phosphorylation by LPS O111:B4 was 5.3-fold higher than levels achieved by LPS O127:B8 (1.5 \pm 2.5 AUs, $P<0.05)$ and 26-fold higher than 

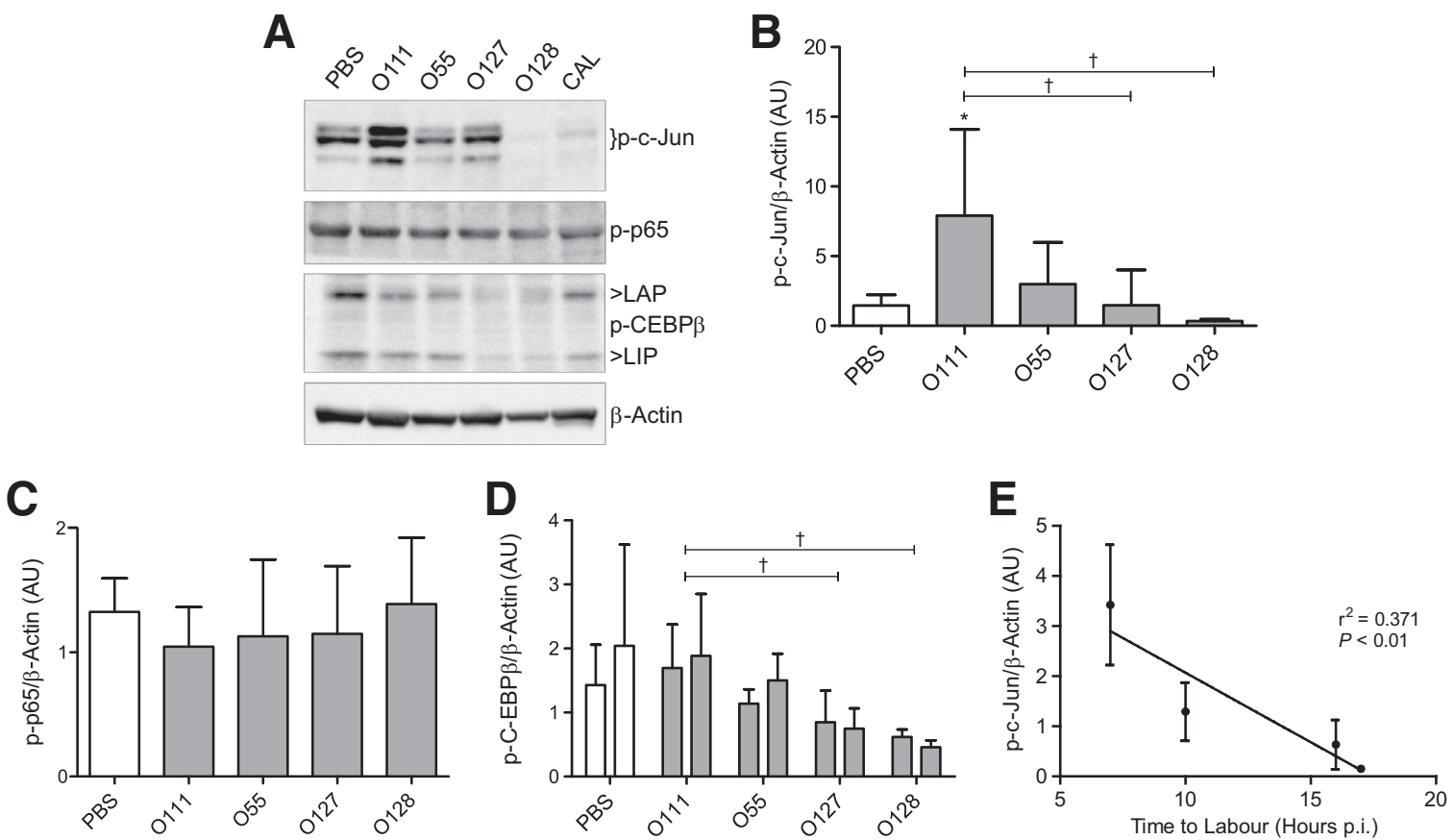

Figure 2 Activation of myometrial activator protein 1 (AP-1) is strongly induced by lipopolysaccharide (LPS) 0111:B4 and precedes the onset of preterm labor. Examination of myometrial protein lysates collected 6 hours after intrauterine injection of either phosphate-buffered saline (PBS) or LPS (serotypes 0111:B4, 055:B5, 0127:B8, or 0128:B12). Results were analyzed by Western blot analysis for the transcriptionally active phosphorylated forms of AP-1 subunit C-jun (A and B), NF-KB subunit p65 (A and C), and CCAAT/enhancer-binding protein (C/EBP $\beta$ ) isoforms, liver-enriched activating protein (LAP; first column) and liver-enriched inhibitory protein (LIP; second column) (A and $\mathbf{D})$. Densitometric analysis of immunoreactive protein reveals an increase in p-C-Jun (B), but not p-p65 (C) or C/EBP $\beta$ isoforms (D), compared with PBS controls. Linear regression of $p$-c-Jun levels against time to labor shows a correlation between high levels of myometrial $p$-c-Jun and rapid onset of preterm labor (E). $n=5(\mathrm{E}) .{ }^{*} P<0.05$, versus PBS-injected control dams; ${ }^{\dagger} P<0.05$, within LPS treatment group (one-way analysis of variance with Tukey's post hoc analysis). AU, arbitrary unit; CAL, calibrator; p.i., postinjection.

LPS O128:B12 $(0.3 \pm 0.1$ AUs, $P<0.05)$. No difference in AP-1 activation was observed in animals treated with O55:B5 $(3.0 \pm 3.0$ AUs), O127:B8, or O128:B12 compared with PBS-injected control dams ( $2.3 \pm 1.6$ AUs). Levels of activated $\mathrm{NF}-\kappa \mathrm{B}$ in control and treated animals remained largely unchanged, as assessed by detection of phosphorylated p65 (Figure 2, A and C). Although the levels of C/EBP $\beta$ activation between PBS control and LPS-treated animals also remained unchanged, significantly less phosphorylation of both the transcriptionally active C/EBP $\beta$ isoform, liverenriched activator protein (LAP), and the functional LAP antagonist, liver-enriched inhibitory protein (LIP), was observed in the myometrium of dams treated with O127:B8 (LAP, $0.8 \pm 0.5$ AUs; LIP, $0.7 \pm 0.3$ AUs) and O128:B12 (LAP, $0.6 \pm 0.1$ AUs; LIP, $0.5 \pm 0.1$ AUs) compared with O111:B4-treated animals (LAP, $1.7 \pm 0.7$ AUs; LIP, $1.9 \pm 1.0$ AUs) (Figure 2, A and D). Linear regression analysis showed a moderate correlation $\left(r^{2}=0.37, P<0.001\right)$ (Figure 2E) between p-c-Jun levels and labor onset, where higher levels of p-c-Jun are associated with rapid onset.

\section{E. coli LPS Serotypes Induce Variable Expression of Proinflammatory and Procontractile Genes in Mouse Myometrium}

To investigate the LPS serotype-specific effects on the acquisition of a laboring phenotype, real-time quantitative
RT-PCR was used to analyze the myometrial mRNA expression of proinflammatory and procontractile genes 6 hours after intrauterine injection of vehicle control or LPS serotypes. Compared with PBS control, an increase in mRNA of the key labor-associated genes encoding the prostaglandin synthase enzyme Cox-2 was observed after LPS O111:B4 (21.1-fold change, $P<0.001)$, O55:B5 (15.5-fold change, $P<0.001)$, O127:B8 (20.1-fold change, $P<0.001$ ), and O128:B12 (6.8-fold change, $P<0.01)$ injection (Figure 3A). Furthermore, induction of Cox-2 mRNA was 3.1-fold higher in LPS O111:B4-treated animals compared with $\mathrm{O} 128$ :B12 $(P<0.05)$.

Cx43 mRNA levels were increased twofold after treatment with O127:B8 $(P<0.01)$ compared with control animals, whereas levels in LPS O55:B5 and O128:B12 remained similar to PBS-injected control mice (Figure 3B). Injection of LPS O111:B4 induced a 1.7-fold increase in Cx43 mRNA expression. An increase in tumor necrosis factor- $\alpha$ (Tnf- $\alpha$ ) mRNA levels was induced by all tested LPS serotypes, with the highest response induced by LPS O111:B4 (11.3-fold change, $P<0.001)$ compared with control (Figure 3C). A similar pattern of Il-1 $\beta$ mRNA induction was observed in response to LPS treatments; however, statistical significance was not reached (Figure 3D). Clear LPS serotype-specific activation of Il-6 mRNA was detected, with LPS O111:B4 eliciting a 52-fold increase $(P<0.001)$ compared with PBS control animals, whereas 

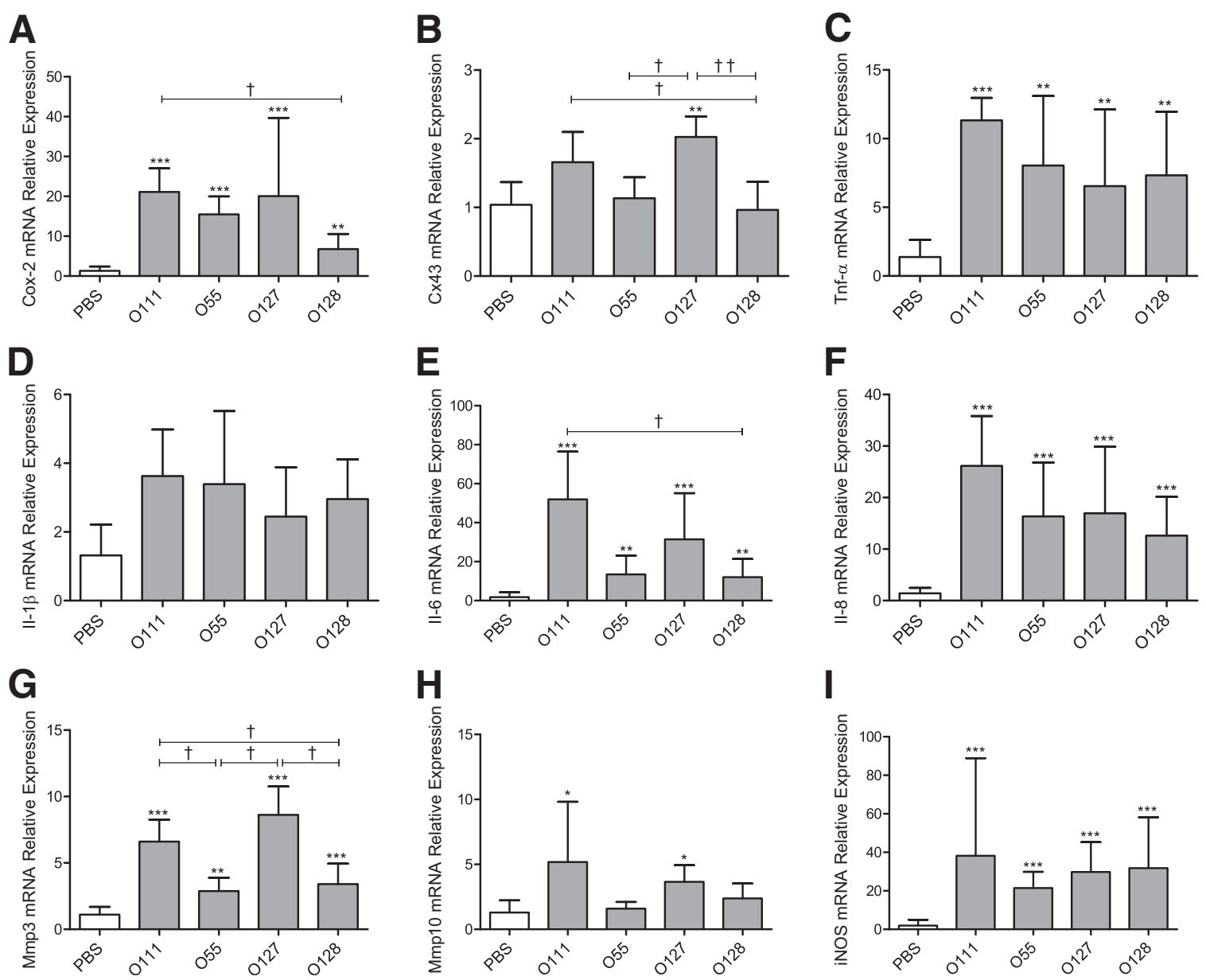

Figure 3 Different serotypes of lipopolysaccharide (LPS) induce variable expression of proinflammatory and procontractile genes in mouse myometrium. Dams were sacrificed at 6 hours after intrauterine injection, and tissue was harvested for real-time quantitative RT-PCR analysis of procontractile and inflammatory genes associated with labor onset, including cyclooxygenase 2 (Cox-2; A), Cx-43 (B), tumor necrosis factor- $\alpha$ Tnf- $\alpha$ (C), Il-1 $\beta$ (D), Il-6 (E), Il-8 (F), matrix metalloproteinase $3(\mathrm{Mmp} 3 ; \mathbf{G})$, Mmp10 $(\mathbf{H})$, and inducible nitric oxide synthase (iNOS; I) mRNA. Data are presented relative to $\beta$-actin mRNA levels. $n=5$ (A-I). ${ }^{\star} P<0.05,{ }^{*} P<<0.01$, and ${ }^{* * *} P<0.001$, versus phosphate-buffered saline (PBS) -injected control dams; ${ }^{\dagger} P<0.05,{ }^{\dagger \dagger} P<0.01$, within LPS treatment group (one-way analysis of variance with Tukey's post hoc analysis).

O55:B5, O127:B8, and O128:B12 induced a 14-fold $(P<0.01)$, 31-fold $(P<0.001)$, and 12-fold $(P<0.01)$ increase compared with control levels (Figure 3E). Levels of Cxcl2 mRNA, the functional murine homologue of the human IL 8 gene (referred to as Il-8 herein), consistently increased between 13 -fold and 26-fold $(P<0.001)$ after all LPS serotype treatments compared with PBS control-treated dams (Figure 3F).

mRNA levels of the extracellular matrix degradation enzymes, metalloproteinases Mmp3 and Mmp10, increased in a LPS serotype-dependent manner. Although all serotype treatments promoted Mmp3 mRNA expression compared with control levels, LPS O111:B4 (6.6-fold increase, $P<0.001$ ) and O127:B8 (8.6-fold change, $P<0.001)$ led to significantly higher induction than O55:B5 (2.9-fold) or O128:B12 (3.4-fold) (Figure 3G). Similarly, levels of Mmp10 mRNA expression significantly increased 6 hours after injection with LPS O111:B4 (5.2fold change, $P<0.05$ ) and O127:B8 (3.7-fold change, $P<0.05$ ), yet no change in Mmp10 mRNA levels was observed between control and O55:B5 or O128:B12 treatments (Figure $3 \mathrm{H}$ ). mRNA levels of inducible nitric oxide synthase (iNOS) consistently increased after treatment with LPS O111:B4 (38.2-fold change, $P<0.001)$, O55:B5 (21.5-fold change, $P<0.001)$, O127:B8 (29.8-fold change, $P<0.001$ ), and O128:B12 (31.8-fold change, $P<0.001$ ) (Figure 3I).

\section{Characterization of LPS Serotype-Specific Modulation of Inflammatory and Uterine Activation Associated Proteins in the Myometrium}

By using Western blot analysis, we next assessed the levels of proteins associated with uterine activation in the myometrium of animals administered the differing LPS serotypes or PBS control. To achieve this, dams on E16 were sacrificed 6 hours after intrauterine injection of PBS control or LPS serotypes O111:B4, O55:B5, O127:B8, or O128:B12, and myometrium protein lysates were analyzed for the key inflammatory mediator, IL-1 $\beta$, and the uterine activation associated proteins COX-2 and CX43. Densitometric analysis of immune-reactive 
A

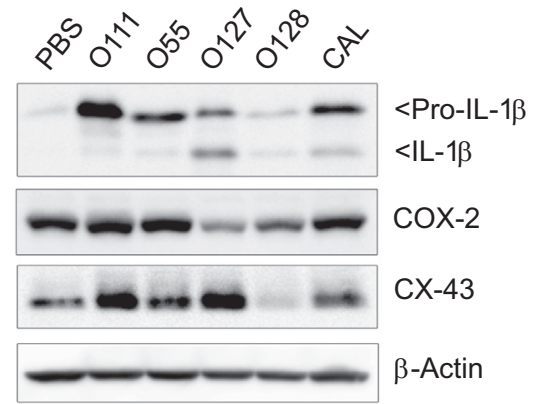

B

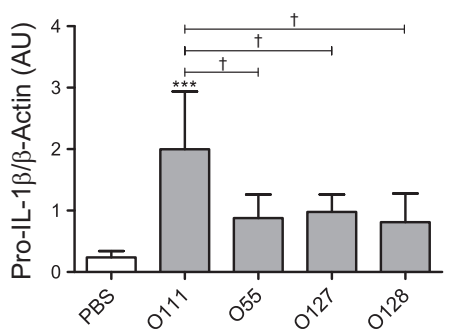

C

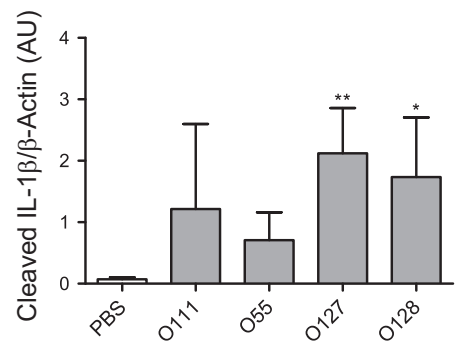

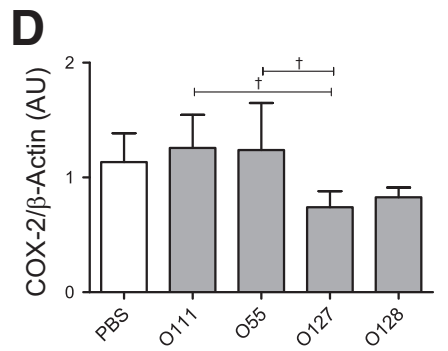

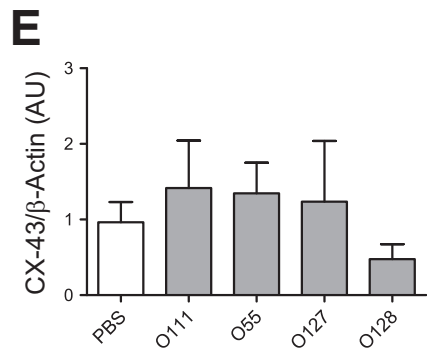

Figure 4 Changes in levels of proteins associated with uterine activation in the mouse myometrium after different lipopolysaccharide (LPS) serotype treatments. Protein levels of IL-1 $\beta(\mathbf{A}-\mathbf{C})$, cyclooxygenase 2 (COX-2; A and D), and CX-43 (A and E) were examined using Western blot analysis in myometrial protein lysates collected from pregnant mice 6 hours after phosphate-buffered saline (PBS) or LPS intrauterine injection. Differing protein levels of pro-IL-1 $\beta$ and cleaved IL-1 $\beta$ are detected in samples treated with the various LPS serotypes (B and C). Differing degrees of COX-2 expression are also observed. $n=5$ (A-E). ${ }^{*} P<0.05,{ }^{*} P<0.01$, and ${ }^{* * *} P<0.001$, versus PBS-injected control dams; ${ }^{\dagger} P<0.05$, within LPS treatment group (one-way analysis of variance with Tukey's post hoc test). AU, arbitrary unit; CAL, calibrator.

protein revealed that levels of the IL-1 $\beta$ precursor, pro- $\mathrm{IL}-1 \beta$ (relative molecular mass $=31,000$ ), significantly increased by LPS O111:B4 compared with PBS-treated animals $(2.0 \pm 0.9$ and $0.2 \pm 0.1$ AUs, respectively; $P<0.001$ ). In addition, LPS O111:B4 significantly increased the expression of pro-IL-1 $\beta$ compared with O55:B5 $(0.8 \pm 0.3$ AUs, $P<0.05)$, O127:B8 $(1.0 \pm 0.2$ AUs, $P<0.05)$, and O128:B12 $(0.9 \pm 0.4$ AUs, $P<0.05$ ) (Figure 4, A and B). Increased cleavage (relative molecular mass $=28,000$ ) of IL-1 $\beta$ compared with PBS $(0.1 \pm 0$ AUs $)$ was observed after LPS O127:B8 $(2.1 \pm 0.7$ AUs, $P<0.01)$ and O128:B12 $(1.7 \pm 1.0$ AUs, $P<0.05)$ treatments (Figure 4, A and C). In contrast to mRNA levels, protein expression of COX-2 was unchanged with LPS O111:B4 and O55:B5 compared with control $(1.1 \pm 0.3$ AUs), but decreased levels were detected in the myometrium of those animals administered 0127:B8 $(0.7 \pm 0.1$ AUs $)$ compared with O111:B4 $(1.3 \pm 0.3$ AUs, $P<0.05)$ or O128:B12 (0.8 \pm 0.1 AUs) compared with O55:B5 (1.2 \pm 0.4 AUs, $P<0.05$ ) (Figure 4, A and D). Levels of total CX43 remained similar in all treatment groups (Figure 4, A and E).

\section{Characterization of AP-1 and NF- $\kappa \mathrm{B}$ Activation in} Neonatal Brain in Response to Upper-Uterine Injection of Differing $E$. coli LPS Serotypes

To investigate the potential mechanism of LPS-induced fetal death observed with specific LPS serotype treatments, the activation pattern of the proinflammatory transcription factors, AP-1, NF- $\kappa$ B, and $\mathrm{CEBP} / \beta$, was assessed. Pup brains were harvested from pregnant mice 6 hours following injection of PBS control or specific LPS serotype, and Western blot analysis was used to assess phosphorylation of the AP-1 subunit, p-c-jun, the NF- $\kappa \mathrm{B}$ subunit, p-p65, and the LIP and LAP isoforms of CEBP/ $\beta$ (Figure $5, \mathrm{~A}-\mathrm{C}$ ). No change in the levels of p-c-jun or p-p65 was identified in pup brain after LPS administration (Figure 5, A and B). The $\mathrm{CEBP} / \beta$ isoforms LIP and LAP were not detected in pup brain protein lysates (Figure $5 \mathrm{~A}$ ).

\section{Effect of LPS Serotypes on Inflammatory Gene Expression in the Neonatal Brain}

Evidence suggests that activation of inflammatory pathways in the neonatal brains is the primary cause of neonatal brain injury in the context of PTL. ${ }^{32,33}$ By using real-time quantitative RT-PCR, we explored the gene expression pattern of inflammatory cytokines (Il-6, Il-8, Il-1 $\beta$ and Tnf- $\alpha$ mRNA) whose exacerbated expression in neonatal brain during the gestational period has been implicated in the development of fetal inflammatory response syndrome, leading to a broad spectrum of neurodevelopmental disorders after birth. ${ }^{34}$ Additional neuronal markers for brain damage, including glial fibrillary acidic protein (Gfap mRNA) and myelin proteolipid protein (Plp mRNA), as well as inducible nitric oxide synthase (iNOS) and endothelial Nos (Nos3), were assessed. LPS O111:B4 treatment caused a significant increase in Il-8 mRNA levels in the neonatal brain compared with control (6.6-fold change, $P<0.01$ ), and 
A

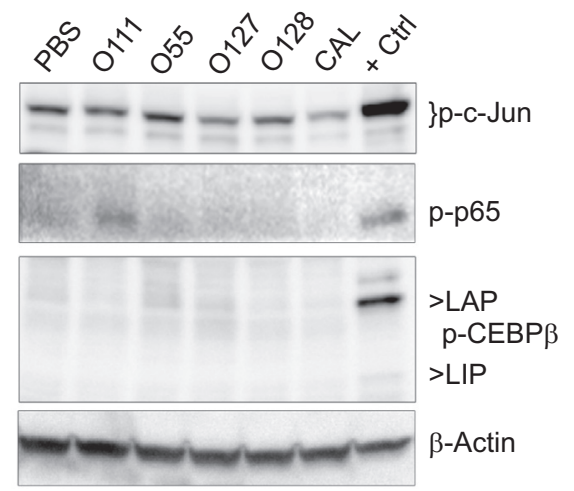

B

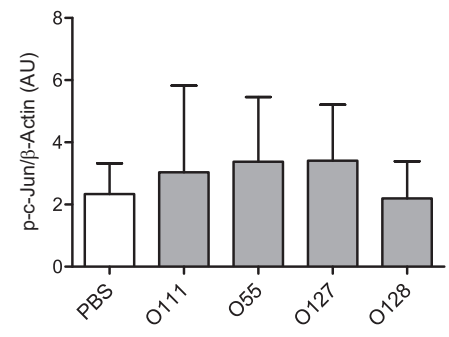

C

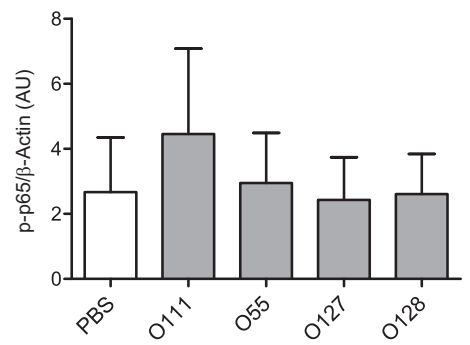

Figure 5 Levels of activated activator protein 1 and NF- $\mathrm{KB}$ remain largely unchanged in neonatal brain in response to upper-uterine injection of lipopolysaccharide (LPS) serotype. Whole neonatal brain tissue extracts, collected 6 hours after intrauterine injection of either phosphate-buffered saline (PBS) or LPS serotypes 0111:B4, 055:B5, 0127:B8, or 0128:B12, were assessed by Western blot analysis for p-C-Jun (A and B) and p-p65 (A and C). No changes in inflammatory transcription factor activation in response to PBS or LPS administration are observed at 6 hours after treatment. Densitometric analysis of immune-reactive bands was performed relative to $\beta$-actin (one-way analysis of variance with Tukey's post hoc test). $n=5(\mathbf{A}-\mathbf{C})$. AU, arbitrary unit; CAL, calibrator; C/EBP, CCAAT/enhancer-binding protein; Ctrl, control; LAP, liver-enriched activator protein; LIP, liver-enriched inhibitory protein.

this increase was also significantly higher compared with O128:B12 treatment $(4.1$-fold change, $P<0.01)$ (Figure 6A).

No significant changes were detected in the levels of Il-6, Tnf- $\alpha$, and Il-1 $\beta$ mRNA after LPS treatment (Figure 6, B-D). Maternal LPS administration did not alter expression of any of the assessed brain damage markers in the neonatal brains (Figure 6, E-H). Similar results were observed in samples collected from pups isolated 4 hours after LPS O111:B4 intrauterine injection, where only IL-1 $\beta$ was significantly increased compared with PBS (3-fold change, $P<0.05$ ), before any fetal demise being observed (Supplemental Figure S1). Efforts were made to assess protein levels of both full-length and cleaved IL-1 $\beta$ in pup brain protein extracts; however, immune-reactive protein was not detected (Supplemental Figure S2).

\section{Discussion}

\section{LPS Serotype Structure, Function, and Route of Administration}

In this study, we investigated the effects of four different E. coli LPS serotypes (O111:B4, O55:B5, O127:B8, and O128:B12) in a murine model of infection- and inflammationinduced PTL. Intrauterine injection was selected as the route of administration because it best mimics the most observed clinical scenario of decidua/myometrial infection, which is responsible for $25 \%$ to $40 \%$ of all preterm births. ${ }^{35,36} \mathrm{We}$ specifically chose LPS purified from $E$. coli because it is the most frequently used LPS isolate in the context of infectionand inflammation-induced preterm birth models, and because colonization of the maternal vaginal flora and urinary tract by $E$. coli is associated with increased rate of PTL and poor pregnancy outcomes. ${ }^{37,38}$ Furthermore, E. coli is the bacteria most frequently isolated from neonates who develop sepsis or meningitis postpartum. ${ }^{39}$

Our data clearly show that, although all serotypes tested lead to PTL, latency between time of injection and onset of labor markedly varied between serotypes administered. These data suggest that subtle changes in the sugar composition of the O-antigen possess the ability to differentially activate functional pathways that precede myometrial activation and labor onset. Detection of LPS from Gram-negative bacteria, such as $E$. coli, is achieved primarily through its interaction with TLR4, which is expressed in the myometrium and other gestational tissues. ${ }^{21,40}$ Bäckhed et $\mathrm{al}^{41}$ have previously shown a contribution of LPS substructures to its endotoxic properties, indicating that the polysaccharide $\mathrm{O}$-antigen element may interfere with lipid A recognition by the TLR4 receptor complex. Structural variances in the Oantigen may thus change the interaction of LPS molecules with the TLR4 receptor complex, possibly resulting in differential activation of downstream inflammatory pathways. Evidence for this includes the acquisition of bacterial immune evasion properties through modulation of O-antigen composition that alters macrophage recognition and phagocytosis of LPS molecules. ${ }^{42,43}$

\section{Impact of LPS Serotype on Maternal and Fetal Outcome}

Our data show the existence of a relationship between latency from LPS injection to labor onset and pup survival rates. LPS O111:B4 induced the most rapid PTL onset (7 hours p.i.) and was accompanied by $100 \%$ fetal death at 6 hours after administration. In contrast, animals injected with LPS O128:B12 delivered 17 hours p.i. with 100\% pup survival. Similar rates of infection- and inflammation-induced preterm birth are achieved in mice when administered $25 \mu \mathrm{g}$ per mouse LPS O111:B4 i.p. on either E16 or E17. ${ }^{18}$ Yet, in this 
A

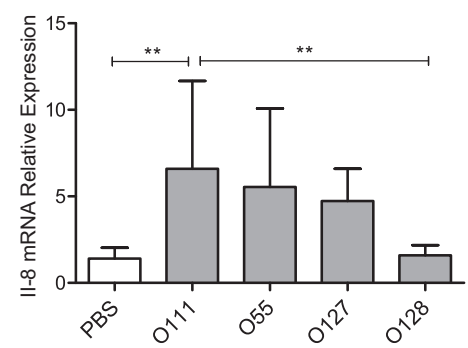

D

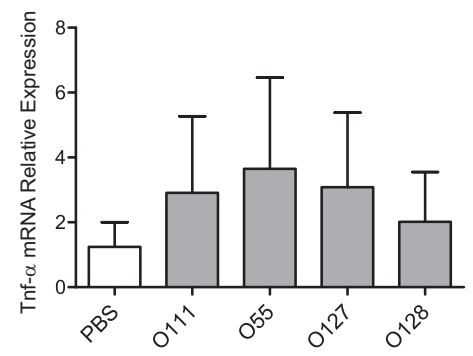

G

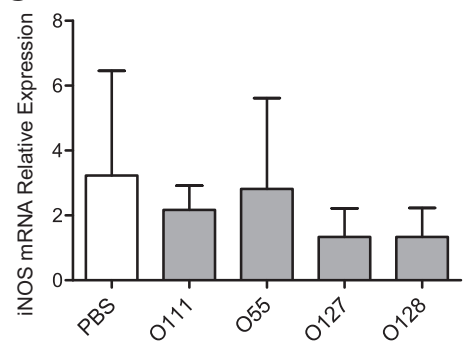

B

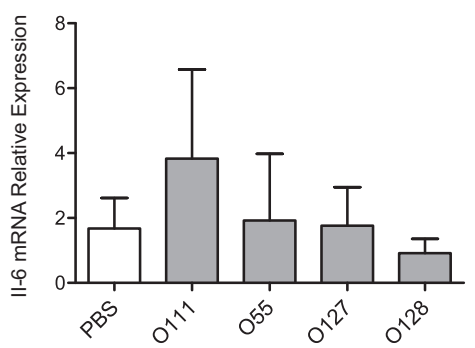

E

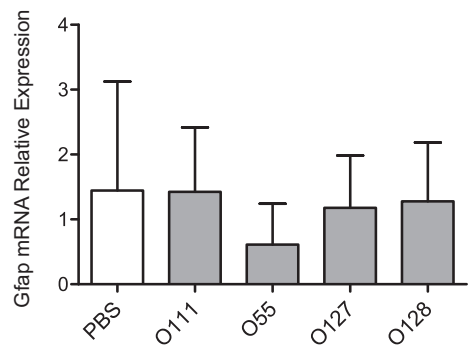

H

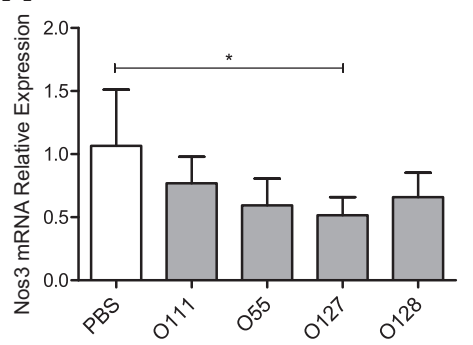

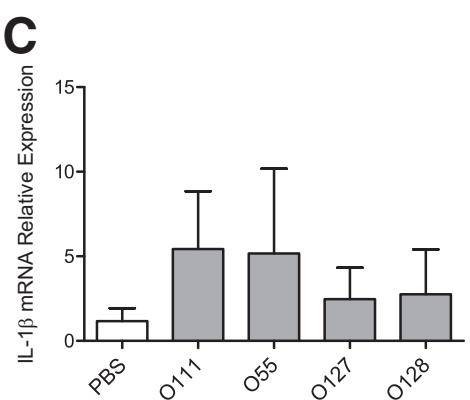

F

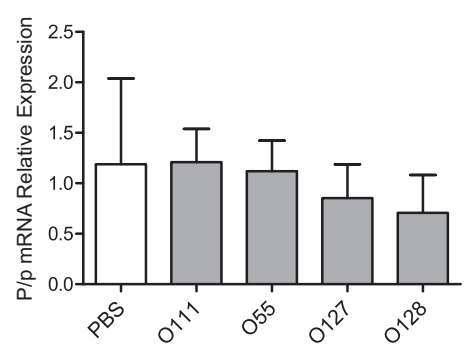

Figure 6 Effect of different lipopolysaccharide (LPS) serotypes on inflammatory gene expression in the fetal brain tissue. Expression of the mRNA of inflammatory genes, Il-8 (A), Il-6 (B), Il-1 $\beta$ (C) Tnf- $\alpha$ (D), neutropic factors including glial fibrillary acidic protein (Gfap E), proteolipid protein (Plp F), inducible nitric oxide synthase (iNOS; G), and endothelial Nos (Nos3; H), was assessed by real-time quantitative RT-PCR in fetal brain tissue collected 6 hours after surgery from mice injected with either phosphate-buffered saline (PBS) or LPS (serotypes 0111:B4, 055:B5, 0127:B8, or 0128:B12). Data are presented relative to $\beta$-actin mRNA levels. $n=5(\mathbf{A}-\mathbf{H}) .{ }^{*} P<0.05,{ }^{* *} P<0.01$ (one-way analysis of variance with Tukey's post hoc test).

model, pup survival rates are reduced from $58 \%$ at E17 to $39 \%$ at E16, suggesting a correlation between gestational age and survival rate. In our study, pup survival rates were consistently assessed on E16, precisely 6 hours after LPS administration, and show that despite sharing the same gestational age, offspring were differentially susceptible to intrauterine fetal death, depending on the serotypes used to induce PTL. These data indicate that fetal death is influenced by LPS serotype and should be considered when designing studies aimed to investigate fetal outcome in the context of infection- and inflammation-induced PTL.

\section{LPS Serotypes Differentially Activate Uterine Inflammatory Pathways}

To gain a better understanding of the potential mechanisms underlying the observed maternal response to LPS serotype, we examined the activation of key inflammatory transcription factors known to regulate inflammatory and contractile pathways in the myometrium at the time of labor onset. We demonstrated that latency to labor after LPS injection correlates with the degree of AP-1 activation, but there is no activation of NF- $\kappa \mathrm{B}$ or $\mathrm{C} / \mathrm{EBP} \beta$. This is consistent with our recent findings showing that murine PTL induced by intrauterine injection of LPS serotype O111:B4 is characterized by AP-1 activation and does not require NF- $\kappa \mathrm{B}$ activation. ${ }^{9}$ Our data, therefore, provide further evidence that AP-1 activation is a critical regulator of the terminal pathways or labor onset. However, inflammatory transcription factor activation varied greatly between LPS-serotype treatment, as did downstream activation of associated inflammatory and contraction genes and proteins. For example, LPS O111:B4 treatment led to the most rapid and potent stimulation of AP-1 and, consequently, the most robust stimulation of Tnf- $\alpha$, Il- 6 , Il-8, and Mmp10 mRNA. Although substantially less AP-1 activation was observed in the myometrium collected from LPS 0127:B8 treated animals, robust increases in mRNA levels of Tnf- $\alpha$, Il-6, Il-8, and Mmp10, as well as Cx-43 and Mmp3, were detected at 6 hours p.i. These results allude to differences in transcriptional regulation of inflammatory pathway activation induced by the different LPS serotypes. These differences appear to extend to protranslational 
regulation of proteins involved in contractility and inflammation. For example, although comparable levels of Il- $1 \beta$ mRNA were observed between LPS treatments, significant differences in the levels of pro-IL-1 $\beta$ and cleaved IL- $1 \beta$ were identified. Protein expression levels of the proinflammatory cytokine IL- $1 \beta$ were significantly increased by LPS O111:B4 treatment. IL-1 $\beta$ is synthetized as a precursor of $31 \mathrm{kDa}$ that undergoes cleavage after activation of the inflammasome complex. ${ }^{44}$ The inflammasome activation yields the production of a $28-\mathrm{kDa}$ intermediate product that is retained in the cells longer than the mature form and can be detected to infer the production and secretion of the mature IL-1 $\beta$ peptide $(17 \mathrm{kDa}) .{ }^{45}$ It is currently unclear whether these differences represent differing degrees of serotypespecific stimulation of common molecular pathways involved in myometrial contractility and inflammatory response or serotype-specific activation of unique pathways. Production of downstream inflammatory mediators, such as IL-1 $\beta, T N F \alpha$, and COX-2, by specific LPS serotypes could potentiate the inflammatory response via a positive feedback mechanism that could partly account for the maternal and neonatal phenotypic differences observed in this study. Although detailed characterization of the relative contribution of these mediators to inflammatory pathway activation is important, our data nevertheless show that different LPS serotypes differentially modulate TLR4-mediated inflammatory activation and provide evidence that a proportion of the reported variability in preterm birth and pup survival rates in murine models can be attributed to LPS serotype. ${ }^{46-48}$

\section{Impact of LPS Serotypes on Pup Survival and Neonatal Brain Inflammation}

Activation of inflammation in the neonatal brain and subsequent production of inflammatory cytokines, such as IL-1 $\beta$ and TNF- $\alpha$, are correlated with adverse neonatal outcome in premature newborns. ${ }^{33}$ By using an intrauterine injection of LPS to induce preterm birth in the mouse, Elovitz et al ${ }^{12}$ previously reported activation of type 1/type 2 helper T-cell cytokines and inflammatory markers in the fetal pup brain 6 hours after injection using a high dose of $250 \mu \mathrm{g}$ LPS O55:B5. ${ }^{14}$ A low-dose intrauterine injection of $50 \mu \mathrm{g}$ LPS O55:B5 results in a modest increase of inflammatory mRNA markers in the pup brain 7 days after delivery. The comparatively low dose of LPS used in our study to induce preterm birth may partly explain the lack of observable differences in levels of phosphorylated NF- $\kappa \mathrm{B}$ and AP-1 in pup brain extracts at 6 hours after injection of $20 \mu \mathrm{g}$ LPS O111:B4 and increase in one (Il-8 mRNA) of the eight inflammatory and brain injury markers assessed in the pup brain. It is possible that activation of inflammatory transcription factors in the pup brain occurs before the 6hour sampling time point examined in this study. We have recently shown that myometrial activation of AP-1 after LPS O111:B4 occurs as early as 1 hour after injection. ${ }^{9}$ The onset of PTL 7 hours after injection of LPS O111:B4 may not be a sufficiently long enough time to permit development of a detectable inflammatory response in the fetal brain. Conversely, it is possible that pup brain inflammation may be detectable in animals treated with LPS O55:B5, O127:B8, or O128:B12 at later stages after injection. Regardless, the marked difference in fetal loss rates between LPS serotypes has important significance for studies using LPS as a model of neonatal brain inflammation and injury.

It has been proposed that intrauterine fetal death in response to LPS treatment may occur because of maternal factors that influence susceptibility to LPS and efficiency of LPS migration through the placenta to the fetus. ${ }^{49}$ Maternally produced inflammatory mediators may then cross the placenta to the fetus and elicit Fas-mediated apoptosis of placental cells. ${ }^{50}$ This may provide a potential mechanism for the increased Il-8 mRNA levels observed in the pup brain and the difference in neonatal outcomes observed in our study in the absence of any inflammatory transcription activation.

\section{Clinical Relevance of LPS Serotype-Specific Inflammatory Responses in Preterm Birth}

Our findings that E. coli-derived LPS serotypes elicit specific activation of TLR4-mediated inflammatory activation in the pregnant host and neonate may be of important clinical relevance. Bacterial serotypes represent different variations within species that are classified primarily because of surface antigen properties. Subspecies classification of bacteria on the basis of serotype has long been recognized as an important determinate of clinical outcome. For example, group B streptococci (Streptococcus agalactiae) are recognized as the leading cause of serious bacterial infections in neonates. ${ }^{51,52} \mathrm{~A}$ difference in group B streptococci virulence is associated with production of serotype-specific capsular polysaccharide, which inhibits deposition of host complement factor $\mathrm{C} 3 \mathrm{~b}$ and subsequent opsonophagocytosis. ${ }^{53}$ Similarly, pneumococcal isolates of serotypes 1 and 5 are associated with invasive disease, whereas serotypes $6 \mathrm{~B}$ and $23 \mathrm{~F}$ are associated with carriage. ${ }^{54,55}$ In identifying and characterizing major differential effects induced by four E.coli serotypes, our data provide evidence that subspecies of bacteria are likely to induce different innate immune response patterns in vivo. Such findings are important considerations for the future design of therapeutics aimed to inhibit specific bacteriainduced inflammatory pathway activation as a strategy to prevent preterm birth and associated neonatal brain damage.

\section{Conclusion}

In conclusion, we provide evidence that specific LPS serotypes induce differential activation of inflammatory transcription factors as well as downstream contractile and inflammatory pathways in both the myometrium and 
neonatal pup brain. Although these data may provide important information that can account, in part, for reported differences in murine models of infection- and inflammation-induced PTL, they also indicate that the use of selective LPS serotypes may provide a useful tool for targeting and exploring specific inflammatory response mechanisms in mouse models of preterm birth.

\section{Supplemental Data}

Supplemental material for this article can be found at http://dx.doi.org/10.1016/j.ajpath.2015.05.015.

\section{References}

1. Liu L, Oza S, Hogan D, Perin J, Rudan I, Lawn JE, Cousens S, Mathers C, Black RE: Global, regional, and national causes of child mortality in 2000-13, with projections to inform post-2015 priorities: an updated systematic analysis. Lancet 2015, 385:430-440

2. MacIntyre DA, Sykes L, Teoh TG, Bennett PR: Prevention of preterm labour via the modulation of inflammatory pathways. J Matern Fetal Neonatal Med 2012, 25(Suppl 1):17-20

3. Romero R, Espinoza J, Goncalves LF, Kusanovic JP, Friel LA, Nien JK: Inflammation in preterm and term labour and delivery. Semin Fetal Neonatal Med 2006, 11:317-326

4. Dammann O, Leviton A: Inflammatory brain damage in preterm newborns: dry numbers, wet lab, and causal inferences. Early Hum Dev 2004, 79:1-15

5. Wu YW, Colford JM Jr: Chorioamnionitis as a risk factor for cerebral palsy: a meta-analysis. JAMA 2000, 284:1417-1424

6. Khanjani S, Kandola MK, Lindstrom TM, Sooranna SR, Melchionda M, Lee YS, Terzidou V, Johnson MR, Bennett PR: NFkappaB regulates a cassette of immune/inflammatory genes in human pregnant myometrium at term. J Cell Mol Med 2011, 15:809-824

7. Khanjani S, Terzidou V, Johnson MR, Bennett PR: NFkappaB and AP-1 drive human myometrial IL8 expression. Mediators Inflamm 2012, 2012:504952

8. Lee YS, Terzidou V, Lindstrom T, Johnson M, Bennett PR: The role of CCAAT/enhancer-binding protein beta in the transcriptional regulation of COX-2 in human amnion. Mol Hum Reprod 2005, 11: $853-858$

9. MacIntyre DA, Lee YS, Migale R, Herbert BR, Waddington SN, Peebles D, Hagberg H, Johnson MR, Bennett PR: Activator protein 1 is a key terminal mediator of inflammation-induced preterm labor in mice. FASEB J 2014, 28:2358-2368

10. Bakos J, Duncko R, Makatsori A, Pirnik Z, Kiss A, Jezova D: Prenatal immune challenge affects growth, behavior, and brain dopamine in offspring. Ann N Y Acad Sci 2004, 1018:281-287

11. Burd I, Chai J, Gonzalez J, Ofori E, Monnerie H, Le Roux PD, Elovitz MA: Beyond white matter damage: fetal neuronal injury in a mouse model of preterm birth. Am J Obstet Gynecol 2009, 201:279. e1-279.e8

12. Elovitz MA, Brown AG, Breen K, Anton L, Maubert M, Burd I: Intrauterine inflammation, insufficient to induce parturition, still evokes fetal and neonatal brain injury. Int J Dev Neurosci 2011, 29: 663-671

13. Elovitz MA, Mrinalini C: Animal models of preterm birth. Trends Endocrinol Metab 2004, 15:479-487

14. Elovitz MA, Mrinalini C, Sammel MD: Elucidating the early signal transduction pathways leading to fetal brain injury in preterm birth. Pediatr Res 2006, 59:50-55

15. Elovitz MA, Wang Z, Chien EK, Rychlik DF, Phillippe M: A new model for inflammation-induced preterm birth: the role of platelet- activating factor and Toll-like receptor-4. Am J Pathol 2003, 163: 2103-2111

16. Golan HM, Lev V, Hallak M, Sorokin Y, Huleihel M: Specific neurodevelopmental damage in mice offspring following maternal inflammation during pregnancy. Neuropharmacology 2005, 48: 903-917

17. Kaga N, Katsuki Y, Obata M, Shibutani Y: Repeated administration of low-dose lipopolysaccharide induces preterm delivery in mice: a model for human preterm parturition and for assessment of the therapeutic ability of drugs against preterm delivery. Am J Obstet Gynecol 1996, 174:754-759

18. Salminen A, Paananen R, Vuolteenaho R, Metsola J, Ojaniemi M, Autio-Harmainen H, Hallman M: Maternal endotoxin-induced preterm birth in mice: fetal responses in toll-like receptors, collectins, and cytokines. Pediatr Res 2008, 63:280-286

19. Schmitz T, Souil E, Herve R, Nicco C, Batteux F, Germain G, Cabrol D, Evain-Brion D, Leroy MJ, Mehats C: PDE4 inhibition prevents preterm delivery induced by an intrauterine inflammation. J Immunol 2007, 178:1115-1121

20. Vyas V, Ashby CR Jr, Olgun NS, Sundaram S, Salami O, Munnangi S, Pekson R, Mahajan P, Reznik SE: Inhibition of sphingosine kinase prevents lipopolysaccharide-induced preterm birth and suppresses proinflammatory responses in a murine model. Am J Pathol 2015, 185:862-869

21. Wang H, Hirsch E: Bacterially-induced preterm labor and regulation of prostaglandin-metabolizing enzyme expression in mice: the role of toll-like receptor 4. Biol Reprod 2003, 69:1957-1963

22. Fitzgerald KA, Rowe DC, Golenbock DT: Endotoxin recognition and signal transduction by the TLR4/MD2-complex. Microbes Infect 2004, 6:1361-1367

23. Rietschel ET, Kirikae T, Schade FU, Mamat U, Schmidt G, Loppnow H, Ulmer AJ, Zähringer U, Seydel U, Di Padova F, Schreier M, Brade H: Bacterial endotoxin: molecular relationships of structure to activity and function. FASEB J 1994, 8:217-225

24. Akarsu ES, Mamuk S: Escherichia coli lipopolysaccharides produce serotype-specific hypothermic response in biotelemetered rats. Am J Physiol Regul Integr Comp Physiol 2007, 292: R1846-R1850

25. Nedrebo T, Reed RK: Different serotypes of endotoxin (lipopolysaccharide) cause different increases in albumin extravasation in rats. Shock 2002, 18:138-141

26. Akarsu ES, Mamuk S, Arat S: Variable antipyretic effect of SC58236, a selective cyclooxygenase (COX)-2 inhibitor, in rats. Adv Exp Med Biol 2003, 525:137-140

27. Dogan MD, Ataoglu H, Akarsu ES: Effects of selective cyclooxygenase enzyme inhibitors on lipopolysaccharide-induced dual thermoregulatory changes in rats. Brain Res Bull 2002, 57:179-185

28. Campos LC, Franzolin MR, Trabulsi LR: Diarrheagenic Escherichia coli categories among the traditional enteropathogenic E. coli O serogroups: a review. Mem Inst Oswaldo Cruz 2004, 99:545-552

29. Nataro JP, Kaper JB: Diarrheagenic Escherichia coli. Clin Microbiol Rev 1998, 11:142-201

30. Pirianov G, Waddington SN, Lindstrom TM, Terzidou V, Mehmet H, Bennett PR: The cyclopentenone 15-deoxy-delta 12,14-prostaglandin $\mathrm{J}(2)$ delays lipopolysaccharide-induced preterm delivery and reduces mortality in the newborn mouse. Endocrinology 2009, 150:699-706

31. Sykes L, Herbert BR, Macintyre DA, Hunte E, Ponnampalam S, Johnson MR, Teoh TG, Bennett PR: The CRTH2 agonist Pyl A prevents lipopolysaccharide-induced fetal death but induces preterm labour. Immunology 2013, 139:352-365

32. Hagberg H, Gressens $P$, Mallard C: Inflammation during fetal and neonatal life: implications for neurologic and neuropsychiatric disease in children and adults. Ann Neurol 2012, 71:444-457

33. Dammann O, Leviton A: Maternal intrauterine infection, cytokines, and brain damage in the preterm newborn. Pediatr Res 1997, 42:1-8

34. McAdams RM, Juul SE: The role of cytokines and inflammatory cells in perinatal brain injury. Neurol Res Int 2012, 2012:561494 
35. Galinsky R, Polglase GR, Hooper SB, Black MJ, Moss TJ: The consequences of chorioamnionitis: preterm birth and effects on development. J Pregnancy 2013, 2013:412831

36. Melville JM, Moss TJ: The immune consequences of preterm birth. Front Neurosci 2013, 7:79

37. Holst E, Goffeng AR, Andersch B: Bacterial vaginosis and vaginal microorganisms in idiopathic premature labor and association with pregnancy outcome. J Clin Microbiol 1994, 32:176-186

38. McDonald HM, O'Loughlin JA, Jolley $\mathrm{P}$, Vigneswaran $\mathrm{R}$, McDonald PJ: Vaginal infection and preterm labour. Br J Obstet Gynaecol 1991, 98:427-435

39. Krohn MA, Thwin SS, Rabe LK, Brown Z, Hillier SL: Vaginal colonization by Escherichia coli as a risk factor for very low birth weight delivery and other perinatal complications. J Infect Dis 1997, 175:606-610

40. Fazeli A, Bruce C, Anumba DO: Characterization of Toll-like receptors in the female reproductive tract in humans. Hum Reprod 2005, 20:1372-1378

41. Bäckhed F, Normark S, Schweda EK, Oscarson S, RichterDahlfors A: Structural requirements for TLR4-mediated LPS signalling: a biological role for LPS modifications. Microbes Infect 2003, 5: 1057-1063

42. Eder K, Vizler C, Kusz E, Karcagi I, Glavinas H, Balogh GE, Vigh L, Duda E, Gyorfy Z: The role of lipopolysaccharide moieties in macrophage response to Escherichia coli. Biochem Biophys Res Commun 2009, 389:46-51

43. Morona R, Daniels C, Van Den Bosch L: Genetic modulation of Shigella flexneri 2a lipopolysaccharide $\mathrm{O}$ antigen modal chain length reveals that it has been optimized for virulence. Microbiology 2003, 149:925-939

44. Martinon F, Burns K, Tschopp J: The inflammasome: a molecular platform triggering activation of inflammatory caspases and processing of proIL-beta. Mol Cell 2002, 10:417-426

45. Wewers MD, Winnard AV, Dare HA: Endotoxin-stimulated monocytes release multiple forms of IL- 1 beta, including a proIL-1 beta form whose detection is affected by export. J Immunol 1999, 162: $4858-4863$
46. Lin Y, Xie M, Chen Y, Di J, Zeng Y: Preterm delivery induced by LPS in syngeneically impregnated BALB/c and NOD/SCID mice. J Reprod Immunol 2006, 71:87-101

47. Xu DX, Wang H, Zhao L, Ning H, Chen YH, Zhang C: Effects of low-dose lipopolysaccharide (LPS) pretreatment on LPS-induced intra-uterine fetal death and preterm labor. Toxicology 2007, 234: $167-175$

48. Lasala N, Zhou H: Effects of maternal exposure to LPS on the inflammatory response in the offspring. J Neuroimmunol 2007, 189:95-101

49. Kohmura Y, Kirikae T, Kirikae F, Nakano M, Sato I: Lipopolysaccharide (LPS)-induced intra-uterine fetal death (IUFD) in mice is principally due to maternal cause but not fetal sensitivity to LPS. Microbiol Immunol 2000, 44:897-904

50. Ejima K, Koji T, Tsuruta D, Nanri H, Kashimura M, Ikeda M: Induction of apoptosis in placentas of pregnant mice exposed to lipopolysaccharides: possible involvement of Fas/Fas ligand system. Biol Reprod 2000, 62:178-185

51. Lin FY, Clemens JD, Azimi PH, Regan JA, Weisman LE, Philips JB 3rd, Rhoads GG, Clark P, Brenner RA, Ferrieri P: Capsular polysaccharide types of group B streptococcal isolates from neonates with early-onset systemic infection. J Infect Dis 1998, 177:790-792

52. Schuchat A: Epidemiology of group B streptococcal disease in the United States: shifting paradigms. Clin Microbiol Rev 1998, 11: 497-513

53. Rubens CE, Wessels MR, Heggen LM, Kasper DL: Transposon mutagenesis of type III group B Streptococcus: correlation of capsule expression with virulence. Proc Natl Acad Sci U S A 1987, 84: $7208-7212$

54. Melin M, Trzcinski K, Antonio M, Meri S, Adegbola R, Kaijalainen T, Kayhty H, Vakevainen M: Serotype-related variation in susceptibility to complement deposition and opsonophagocytosis among clinical isolates of Streptococcus pneumoniae. Infect Immun 2010, 78:5252-5261

55. Rodriguez DS, Rizo AG, Monroy SP, Reyes T: [Antimicrobial susceptibility and serotyping of Pseudomonas aeruginosa isolated from HIV/AIDS patients] Spanish. Rev Cubana Med Trop 2002, $54: 142-146$ 